\title{
Sobre a MPB e a Longevidade
}

José Eduardo Gonçalves Magossi Graduado em Jornalismo pela Universidade de São Paulo (1991), possui especialização na área financeira e também cultural. Atualmente é repórter especial da Agência Estado, onde desenvolve coberturas voltadas para o setor de bioenergia . Paralelamente ao trabalho na imprensa, desenvolve projetos de produção musical junto às gravadoras, resgatando fonogramas e discos raros de Música Popular Brasileira. É mestrando no Programa de Pós-Graduação em Meios e Processos Audiovisuais, da ECA/USP, sob orientação do prof. Dr. Eduardo Vicente. E-mail:

eduardo.magossi@usp.br
Resumo: O presente artigo tem como objetivo elencar os motivos pelos quais a Música Popular Brasileira (MPB) permaneceu em evidência nos últimos 40 anos no cenário musical brasileiro, principalmente a cena formada por artistas como Chico Buarque, Caetano Veloso, Gilberto Gil, Maria Bethânia e Gal Costa. Através da análise das estatísticas de venda de discos produzidas pelo instituto de pesquisa Nopem entre 1965 e 1999, vê-se que estes artistas praticamente nunca deixaram a lista anual dos 50 mais vendidos. Além disso, entre 2000 e 2009 este grupo de artistas também esteve bastante presente em trilhas de novelas da Rede Globo. Entendo que a longevidade destes nomes está vinculada ao fato de, desde seu surgimento, eles terem apresentado propostas musicais diferenciadas e críticas sociais e políticas que lhes deram legitimidade artística e intelectual. Ressalta-se também a importância da televisão na consolidação destes artistas, que deixaram de ser apenas voz e música, para se tornarem imagem, atitude e comportamento.

Palavras-chave: MPB; Música Popular Brasileira; Indústria Fonográfica

Abstracts: This article intends to cast the causes that kept Brazilian Popular Music (MPB, from the portuguese initials) in evidence in the last 40 years in the brazilian musical scene, mostly the scene consisting by artists as Chico Buarque, Caetano Veloso, Gilberto Gil, Maria Bethânia and Gal Costa. Through the analysis of the record selling statistics made by a research institute called Nopem between 1965 and 1999, it is understood that these artists virtually never left the annual top 50 selling records. Moreover, between 2000 and 2009, this group of artists also was a constant presence in the soundtracks of Rede Globo's soap operas. I understand that the longevity of these names is linked to the fact that, since their appearance, they had displayed different musical proposals with social and political critics that gave them intellectual and artistic legitimacy. It has to be highlighted the importance of the television in the consolidation of these artists. With the exposure of the television, they stopped being just voice and music to become image, attitude and behavior.

Keywords: MPB; Brazilian Popular Music; Record Industry 


\section{Uma provocação}

A idéia de escrever o presente artigo surgiu de uma provocação feita pelo professor Eduardo Vicente durante uma aula de sua disciplina "Indústria Fonográfica no Brasil: uma perspectiva histórica", ministrada dentro do Programa de Pós-Graduação em Meios e Processos Audiovisuais, do Departamento de Cinema, Rádio e TV (CTR) da ECA/USP. Vicente destacou o fato de que "diante de tantas homenagens aos 50 anos de Bossa Nova, 40 anos de Jovem Guarda, 20 anos de Rock Brasil e muitos revivals da cena dos anos 80 , da discoteca, e até da música infantil dos anos 80 , por que nunca houve uma homenagem e/ou revival de artistas da MPB 'clássica'"?

Antes de responder a esta provocação, acredito valer a pena esclarecer que, ao citar a MPB clássica, entendo que Vicente se referia aos artistas que consolidaram esta nova forma musical, surgida no decorrer da década de 60 , construída sobre a base estética da bossa nova, com seu cantar informal, quase falado e intimista, com a inclusão de influências de outros ritmos, como o samba, a balada, o xote, o baião, e incorporando instrumentos musicais presentes no rock, como a guitarra elétrica, ao mesmo tempo que manteve um olhar de resgate sobre a música do passado. Esta nova forma musical que nos acostumamos a chamar de MPB, como se ela incluísse toda a "música popular brasileira" da qual rouba a sigla, nasceu chamada de Moderna Música Popular Brasileira e, segundo Favaretto $(2007$, p.5), diferenciava-se também pelos temas propostos. Além das canções de amor e carnaval, passou a abranger protesto político e social, temas regionais e, um pouco mais tarde, durante os anos 70 , referências mais explícitas a questões comportamentais, usando para explorar todos estes temas, um procedimento narrativo diferenciado. Napolitano (2010, p. 5-6) ressalta que, entendida como objeto histórico que articula política e cultura, a MPB reuniu, por volta de 1965, vários estilos e tendências musicais que tinham como objetivo comum atualizar a expressão musical do Brasil. Desta fusão de elementos tradicionais ao estilo bossa novista, juntamente com a exploração de novos temas, nasceria a música que consagraria a sigla MPB.

Entendo que esta MPB inicia seu processo de consolidação como tendência musical a partir dos festivais de música realizados na segunda metade da década de 60, que colocou em evidência uma nova geração de artistas, como Chico Buarque, Caetano Veloso, Gilberto Gil, Nara Leão, Elis Regina, Gal Costa, Jair Rodrigues e Maria Bethânia, entre outros. Estes artistas haviam incorporado a estética mais intimista da bossa nova, como explicado por Napolitano (2010, p.5-6), recriando-a com a inclusão de influências específicas e pessoais. Diante do exposto acima, refaço a provocação de Vicente na seguinte pergunta: Por que nunca houve um revival da MPB representada pelos artistas acima? A resposta, no meu entendimento, é óbvia: porque estes nomes nunca saíram de cena para serem "revividos" ou "relembrados" por homenagens ou ciclos de shows rememorativos.

\section{Longevidade à Luz dos Dados do Nopem}

Ao final deste artigo procuro alinhavar alguns dados que provam que estes artistas se mantiveram em evidência durante os últimos 44 anos, de 1965 a 2009, e o porquê desta manutenção. Para isso, utilizei as estatísticas de venda de discos

${ }^{1}$ Nopem - Nelson Oliveira Pesquisas de Mercado foi um instituto de pesquisas que realizou levantamento de venda de discos junto à lojistas nas cidades do Rio de Janeiro e São Paulo e que listava os 50 álbuns mais vendidos anualmente durante o período de 1965 a 1999. produzidas pelo Nopem - Nelson Oliveira Pesquisas de Mercado ${ }^{1}$ entre 1965 e 1999. As listas do Nopem não trazem quantidades de discos comercializados, apenas os nomes dos 50 títulos mais vendidos por ano, incluindo aí tanto LPs e compactos simples e duplos, sem distinção, a partir da informação de lojistas das cidades de São Paulo e Rio de Janeiro. Apesar das informações serem limitadas, as listas do Nopem constituem-se dos únicos documentos de pesquisa de venda de discos que abrangem o período analisado disponíveis para consulta. 
A análise dos dados do Nopem levou a elaboração das duas tabelas apresentadas aqui. Na primeira, é mostrada uma lista de artistas de MPB que possuam quatro ou mais citações na lista anual dos 50 mais vendidos entre 1965 e 1999. Os artistas que compõem a lista foram definidos através do critério de terem produzido, ao longo de sua carreira, músicas que incluam elementos característicos de mais de um ritmo ou tendência musical. A segunda tabela foi elaborada a partir das estatísticas de venda de discos de apenas cinco artistas: Chico Buarque, Caetano Veloso, Gilberto Gil, Maria Bethânia e Gal Costa. A escolha destes cinco artistas foi feita a partir de alguns critérios: todos surgiram quase ao mesmo tempo em 1965; ao longo de suas carreiras todos praticaram uma mescla de ritmos e tendências musicais absorvidas pela MPB mas sem anular as marcas pessoais de sua obra; todos (com exceção de Bethânia) foram participantes ativos dos festivais de música dos anos 60 e; os cinco artistas gravavam, nos anos 70, para a gravadora Philips, durante a gestão do presidente André Midani. A participação das vendas destes cinco artistas da tabela 2 aparece de forma consolidada na tabela 1 . Ou seja, na tabela 1, estes cinco artistas foram considerados como uma única entidade para comparação com os demais.

Ao analisar a venda de discos de artistas da MPB no período proposto, a primeira constatação a ser feita é a presença de Roberto Carlos em todas as listas entre 1965 e 1999. Embora não seja considerado propriamente um artista da MPB e esteja mais ligado ao movimento da Jovem Guarda, é certo afirmar que Roberto Carlos influenciou os artistas da MPB. Depois de Roberto Carlos, é o conjunto consolidado destes cinco artistas (Chico Buarque, Caetano Veloso, Maria Bethânia, Gal Costa e Gilberto Gil) que surge com maior presença. Apenas nas listas dos anos de 1986, 1996 e 1998 não consta o nome de nenhum deles. Em anos como 1969 e 1976, os cinco estão presentes na lista de mais vendidos. Em anos como 1973 e 1980, quatro nomes estão presentes. Na segunda metade dos anos 90, porém, apenas um nome foi incluído nas listagens anuais, refletindo a perda de participação dos artistas de MPB no mercado de discos para os artistas sertanejos e de pagode. Entre os cinco artistas, Maria Bethânia e Gal Costa são as mais constantes, com 14 citações cada, ou presença em $41 \%$ dos anos. Bethânia aparece em listas entre 1969 e 1994, cobrindo 25 anos. Gal Costa aparece em listas entre 1969 e 1997, perfazendo uma longevidade das paradas do Nopem por 28 anos. Chico Buarque é citado em 13 listas, entre os anos de 1965 e 1994, com permanência de 29 anos. Caetano Veloso e Gilberto Gil têm, cada um, apenas 10 citações cada. Veloso é o mais longevo no Nopem, aparecendo entre 1968 e 1999, no decorrer de 31 anos. Já Gil aparece entre 1969 e 1993, cobrindo 23 anos. É interessante notar que mesmo nos três anos em que estiveram ausentes das listas, estes artistas estiveram presentes indiretamente. Em 1986, um dos discos mais vendidos do Nopem é Radio Pirata ao Vivo, do RPM, cuja canção de trabalho era "London London", de Caetano Veloso. Em 1996, eles também estavam presentes em dois dos discos mais vendidos do ano. Um deles, era Um Brasileiro, disco de Ney Matogrosso que relia a obra de Chico Buarque com a participação do mesmo. O outro era Amigos, de Ângela Maria, que conta com a participação de Caetano, Gal, Bethânia e Chico. Em 1998, a trilha sonora nacional da novela Por Amor, da Rede Globo, era listada e contava com música de Bethânia. Ou seja, mesmo nos anos em que não possuíam discos de carreira nas paradas, os cinco artistas continuavam presentes no cotidiano dos consumidores de música.

É inegável o poder de permanência destes artistas quanto comparados a outros, que ficaram ligados a uma determinada cena ou período, embora muitos continuem atuando até o presente. Veja o caso de Nara Leão e Edu Lobo, por exemplo, que aparecem nas listas apenas três e duas vezes respectivamente, ainda nos anos 60, vinculados a sua participação em festivais. Outras artistas como Amelinha, Baby Consuelo e Elba Ramalho aparecem respectivamente duas, três e quatro vezes, no início dos anos 80 , quando ocorre uma maior evidência de cantoras de viés nordestino. Mesmo artistas considerados de "primeiro time" como Elis Regina 
(oito citações entre 1965 e 1976), Jorge Ben (quatro citações entre 1970 e 1975), Milton Nascimento (sete citações entre 1976 e 1987), Ney Matogrosso (quatro citações entre 1978 e 1996) ou Paulinho da Viola (duas citações entre 1970 e 1974) não atingiram a longevidade dos cinco artistas analisados.

\section{Nas Trilhas Sonoras do Século XXI}

Vale a pena citar a participação destes cinco artistas nas trilhas sonoras das novelas transmitidas pela Rede Globo entre 2000 até o final do primeiro semestre de 2009. As 48 telenovelas transmitidas pela emissora no período analisado possuíam 50 músicas dos cinco artistas em suas trilhas sonoras, considerando-os apenas como intérpretes, de acordo com levantamento feito pelo site www.teledramaturgia. com.br. Destas 50 canções, 18 são interpretadas por Caetano Veloso (quase $40 \%$ das trilhas), 11 por Gal Costa, dez por Maria Bethânia, sete por Chico Buarque e quatro por Gilberto Gil. Vale ressaltar que a pouca presença de Gil está vinculado ao seu afastamento do cenário musical para cumprir suas funções políticas. Neste mesmo período, artistas mais contemporâneos, como Ana Carolina, Zélia Duncan, Skank e Ivete Sangalo conseguiram emplacar, respectivamente, dez, dez, seis e quatro músicas em trilhas da Rede Globo, um número abaixo da média obtida pelo grupo dos 5. Entendo que atualmente a presença destes artistas nas trilhas de novela é uma forma de legitimar a qualidade das mesmas, colocando-se faixas de Caetano, Bethânia, Gal, Chico e Gil ao lado de novos entrantes deste mercado.

\section{Como, Quando e Porquê}

Entendo que está explícita e comprovada pelos dados acima a afirmação de que os artistas de MPB analisados nunca deixaram a cena musical brasileira o que torna a realização de homenagens e revivals desnecessária, o que responde à provocação feita. Porém, gostaria de fazer algumas considerações a respeito dos motivos que fizeram com que este grupo de artistas se mantivesse em evidência por mais de 40 anos:

\section{Artistas com " $\mathrm{A}$ " maiúsculo}

É importante ressaltar o fato de que estes cinco artistas surgiram em um período em que a própria indústria cultural estava dando seus passos iniciais no Brasil e ainda não havia se cristalizado nem criado uma segmentação expressiva. Também é importante lembrar o caráter inovador destes artistas e das propostas apresentadas por eles que foram além da música, ou utilizando a música como instrumento para críticas sociais e políticas. Vale citar as músicas "Carcará", da peça Opinião, interpretado por Maria Bethânia, "Alegria Alegria" e "É Proibido Proibir", que participaram de festivais interpretados por Caetano Veloso, "Domingo no Parque", de Gilberto Gil e "Divino Maravilhoso", interpretado por Gal Costa, também de festivais e "Pedro Pedreiro" e "Roda Viva", de Chico Buarque, todas apresentando letras de forte conteúdo social. Porém, mais que utilizar a música como crítica social e política, estes artistas criaram um processo narrativo em que misturavam descrições dos problemas sociais e políticos ao cotidiano vivido por jovens de classe média. Desta mistura, criou-se uma música que não se enquadrava dentro dos limites do que era conhecido como música, tornando-se difícil reconhecer, por exemplo, sua postura política. Ao referir-se às composições "Alegria, Alegria", de Caetano Veloso, e "Domingo no Parque", de Gilberto Gil, por exemplo, Favaretto $(2007$, p.20) diz que pela primeira vez canções pediam explicações para compreender sua complexidade. Ele diz que "impunha-se, para crítica e público, a reformulação da sensibilidade, deslocando-se, assim, a própria posição da música popular, que, de gênero inferior, passaria a revestir-se de dignidade...".

Esta característica iria tornar-se ainda mais evidente nos anos seguintes, quando a indústria cultural se consolidou. Chico Buarque, Caetano Veloso e Gilberto Gil são 
praticamente os únicos artistas musicais brasileiros a serem exilados pelo governo militar no início dos anos 70 em função de sua postura política. Entendo que esta militância neste momento, ao lado da complexidade artística que apresentavam, criou uma "aura" especial envolvendo estes artistas que os legitimou perante a sociedade como artistas engajados diante de outros alienados, que apenas falavam de coisas de amor. Ao utilizar a "fresta" da canção popular para, nas palavras de Guilherme Wisnik (2005, p.81-82), driblar a ação repressiva da censura, filtrando o lirismo e o prazer resistentes da cultura popular para lançá-los na arena da cultura de massas, estes artistas começaram a ser vistos como, além de artistas, intelectuais, donos de anseios profundos que iam mais longe que a música simplesmente. Wisnik não é o primeiro a utilizar a teoria da "fresta". Foi Vasconcellos (1977) quem primeiro utilizou a expressão "linguagem da fresta", ao se referir à estratégia dos compositores de escreverem letras passíveis de serem duplamente decodificadas e, desta forma, passar pelo crivo dos censores. Ao contrário dos demais cantores de antigamente e atuais alienados, este grupo de artistas mostrou, ao utilizar a estratégia da fresta, ter atingido maturidade social e política que os transcenderam para além do rótulo de simplesmente cantores e compositores. Isto diante da nascente sociedade de consumo.

\section{Carreiras que se legitimam}

A manutenção desta "aura" ao longo dos anos é fruto da própria carreira elaborada por eles, que continuaram ativos em construir uma obra que transcendesse a própria música. Também é importante ressaltar que estes artistas nunca fizeram concessões a modismos e seguiram seus instintos e gostos muitas vezes contrariando a atual cena vigente. Desta forma, Bethânia seguiu destacando-se por um repertório peculiar - onde se misturavam canções nordestinas, pontos de candomblé e baladas românticas - e principalmente por seus shows pontuados por declamações de poetas como Fernando Pessoa e interpretações vigorosas. Além disso, Bethânia uniu-se a diretores de teatro como Fauzi Arap para construir espetáculos conceituais, centrados em um tema, explorado através das músicas e poemas costurados em um fluxo contínuo durante o show. Chico Buarque estendeu suas antenas também para literatura e hoje diz que se considera mais um escritor que um compositor. Gilberto Gil seguiu seu caminho de pesquisa musical, fazendo discos priorizando às vezes os sambas, às vezes o baião, além do rock, pop, reggae, fazendo de cada novo disco o resultado de uma pesquisa, além de intensificar seu lado político a ponto de exercer o cargo de ministro da Cultura durante a administração Lula. Caetano Veloso seguiu sua trajetória mesclando música experimental com aproximação com a música considerada brega. Assim como Gil, mantém-se atento às novas tecnologias ao ponto de elaborar o repertório de seu mais recente álbum, zii e zie, lançado no primeiro semestre de 2009, através de um blog na Internet. Apenas Gal Costa permaneceu mais preguiçosa, tendo conseguido, no meu entendimento, se manter no gosto popular em função de sua voz cristalina e de suas interpretações tecnicamente perfeitas. Porém, a cantora baiana voltou ao mercado musical com um disco vigoroso em 2011, "Recanto", feito apenas com composições de Caetano Veloso e produção de seu filho, Moreno.

\section{O papel da mídia e a televisão}

A mídia também teve papel importantíssimo na manutenção destes artistas em evidência. Estes artistas nasceram no momento em que a televisão se propagava entre a população urbana, ocupando o lugar do rádio como centro de entretenimento doméstico na vida destas pessoas. É importante ressaltar que, neste momento, estes artistas eram jovens fazendo uma música moderna voltada para um público jovem em um novo meio de comunicação, em contraponto com o velho rádio, com seus cantores já antigos, voltados para um público também envelhecido. E estes novos artistas, alavancados em um primeiro momento pelos 
festivais de música transmitidos pela televisão, souberam aproveitar a exposição que esta nova mídia oferecia. A televisão fez com que, além da voz e das músicas, estes artistas pudessem construir uma imagem, importante para assegurar o protagonismo obtido na divulgação musical e também de idéias e atitudes comportamentais. Em participação em programas semanais, ou em seus próprios programas, não era apenas a música que era comentada pelos telespectadores, mas a roupa e o comportamento geral destes artistas. Em entrevista a revista Veja n.10, em novembro de 1968, Caetano comenta que a "roupa...criava um clima para o som".

É interessante notar que estes artistas ocuparam, na mídia, e consequentemente na consciência popular, o papel de formadores de opinião. Mesmo com o passar dos anos, Chico, Caetano e Gil estão sempre entre a elite intelectual ouvida pela mídia sobre assuntos que transcendem a música e resvalam em questões sociais, políticas e culturais. Mas vale ressaltar que este papel já se vislumbrava nos anos 60. Em matéria de capa da revista Realidade de número 8, de novembro de 1966, intitulada "A nova escola do samba", de Narciso Kalili, as declarações de Caetano, Chico e Gil eram valorizadas e destacadas dos mais de 20 artistas ouvidos pela revista. Na revista em questão, Gil dizia: "A nossa música pode ter até pretextos políticos, mas como elementos normais, espontâneos, sem que o compositor faça esse tipo de música somente porque está na moda. Os caminhos são muitos mas o trilho é um só: qualidade. De Caetano, destaco esta fala: "Hoje digo o que sinto, com o aperfeiçoamento musical que adquiri e com a consciência que a realidade brasileira me dá". Chico Buarque chega a fazer uma lista de ações fundamentais necessárias para ele produzir música. Da lista, ressalto a importância dada por Chico ao fato do artista estar situado em sua época e ser participante. Para ele, o artista também tem que voltar para suas raízes "como se os primeiros que fizeram bossa-nova tivessem esquecido alguma coisa que cabe a nós ir buscar". "É preciso sentir os problemas de hoje e traduzir esse sentir nas músicas. A música de protesto intencional é vazia, chata, complexada, passiva", relata ele à revista. Entendo que os relatos acima, entre outros, serviram para mostrar ao público consumidor que estes artistas possuíam escopo para fundamentar as idéias que disponibilizavam ao público em forma de canções.

\section{4. $O$ toque de André Midani}

Não se pode falar na imagem destes artistas sem falar de André Midani, que foi o principal executivo da gravadora Philips (atual Universal) entre 1968 e 1976. Neste período, Midani construiu um elenco poderoso constituído de Chico Buarque, Caetano Veloso, Gilberto Gil, Maria Bethânia, Gal Costa e também Elis Regina, Jair Rodrigues, Ivan Lins, Tim Maia, Jorge Ben e Raul Seixas, entre outros. O executivo ficou conhecido por sua política de dar mais atenção à construção da imagem do artista do que para a própria música. Vicente (2009, p. 128-129) ressalta que Midani afirmara, em uma palestra realizada em 1975 na Associação dos Dirigentes de Vendas e Marketing do Brasil, que a imagem de seu contratado é formada pouco a pouco. Segundo ele, o retorno é menos veloz, mas provavelmente será mais duradouro. Isto explica porque Midani tornava possível, durante sua gestão, a produção de um disco como Araçá Azul, de Caetano Veloso, experimental, em seqüência a outro de sucesso, como Chico e Caetano ao Vivo. Midani conta, em sua biografia, que acreditava serem necessários três discos para "desenvolver" um artista e que conhecer sua alta era tão importante quanto comercializar sua música. Segundo ele, a maneira de se cantar e de um artista apresentar seu trabalho era tão importante quanto o próprio trabalho. Foi Midani (2008, p.42) também que deu a seus contratados, até meados dos anos 70 , maior liberdade para escolher o próprio repertório, sem interferência de produtores que colocavam sempre composições de amigos em suas produções, diferenciando estes artistas da velha guarda, que não tinha este tipo de poder, e também da geração posterior, que sofreu e ainda sofre muita interferência de produtores. 0 
fato é que, 40 anos depois de Midani iniciar sua estratégia, a grande maioria dos artistas citados aqui e que passou por suas mãos continua ativa sem a utilização de recursos de revitalização como revivals, tributos, shows acústicos, encontros históricos, etc. (Vicente, 2009). Midani (2008, p.56) sugere, por exemplo, que foi ele quem teria criado a idéia das trilhas sonoras para telenovelas da Rede Globo que tornaram-se um bom veículo de divulgação de seus artistas. E que, como foi mostrado acima, continua priorizando estes artistas (o grupo dos cinco) até hoje.

\section{O intercâmbio com as novas gerações}

Também é importante citar a característica deste grupo de artistas de sempre estarem abertos para a produção musica das novas gerações. E como esta nova geração direta ou indiretamente sempre procurou a legitimação de sua música por este grupo. É famosa a história de como apenas quando Caetano Veloso cantou uma música de Cazuza ("Todo amor que houver nesta vida") em seu show de 1985, o diretor da Som Livre e pai de Cazuza, João Araújo, reconheceu que seu filho era um verdadeiro artista. Do lado contrário, Caetano também fez hits certeiros para artistas então em começo de carreira como "Nosso Estranho Amor", gravado por Marina e "Menino Deus" para A Cor do Som. Caetano também produziu os primeiros trabalhos de Martnália e Virgínia Rodrigues, por exemplo. Também é comum a participação de Caetano em discos de outros artistas de menor repercussão e de musicalidades díspares, como Vinicius Cantuária, Olodum, Eugênia de Castro e Mello, Negra Li, Afroreggae, Rappin'Hood, Beto Guedes, além de astros internacionais como Luciano Pavarotti e Nelly Furtado. Ao potencializar a comunicação com a nova geração, Caetano acabou incorporando novas técnicas e sonoridades ao seu trabalho ao mesmo tempo que permanece presente na música ofertada para uma nova geração de consumidores através destas participações afetivas. Entre as mais recentes estão sua colaboração com jovens músicos como o guitarrista Pedro Sá, o baterista Marcelo Callado e o baixista Ricardo Dias Gomes, na elaboração e gravação de seus dois mais recentes álbuns de estúdio, "Cê" e "zii e ziê", e na união com a grande sensação da MPB de 2010, Maria Gadú, em turnê que acabou gerando a gravação de CD e DVD ao vivo. Uma outra forma de permanecer é através de regravações de artistas contemporâneos, como ocorreu quando o RPM regravou "London London" em 1986.

Essa comunicação em uma via de mão dupla com a nova geração também foi praticada pelos outros artistas do grupo. Bethânia sempre fez participações afetivas em discos de outros artistas mais jovens, seja de uma popstar como Ivete Sangalo como de uma iniciante Margareth Menezes ou de um desconhecido músico mineiro chamado Thelmo Lins. Bethânia também sempre procurou gravar canções de novos compositores, como Adriana Calcanhotto e Ana Carolina mais recentemente e, nos anos 70, Sueli Costa e Gonzaguinha, por exemplo. Chico Buarque também costuma dar canjas em discos de novos artistas. É importante lembrar que foi Chico que apresentou para o grande público artistas como Elba Ramalho e Zizi Possi. Nos últimos cinco anos, Chico participou de discos de Fernanda Porto, Dado Villa-Lobos, Nilze de Carvalho, Paula Santoro, Liv Moraes e de artistas internacionais como Pablo Milanez e Omara Portuondo, ampliando o seu público potencial. Entendo que esta abertura para fazer trabalhos com artistas novos provoca a admiração dos novos entrantes neste mercado sem que a admiração de seus pares seja afetada. Em 2011, Chico surpreendeu o público presente na estreia de seu mais recente espetáculo, ao adicionar na letra de "Cálice", composição sua e de Gil que remete à ditadura militar, novas letras feitas pelo rapper Criolo, dando novo contexto à canção. Ao cantar os versos de Criolo, "Afasta de mim a biqueira, pai. Afasta de mim, as biate, pai. Afasta de mim a coqueine, pai", Chico não só se aproxima de uma nova geração ao abordar seus problemas, como também legitima estes novos artistas e ao fazê-lo, consegue se manter no mainstream, prolongando sua longevidade no mercado musical. 


\section{Participação na legitimação da cena infantil}

Vale lembrar também que, no início dos ano 80, quando a indústria fonográfica decidiu criar uma cena infantil, ela foi buscar legitimação deste trabalho em artistas da MPB. Desta forma, antes de se consolidar com artistas próprios, os primeiros discos desta cena infantil traziam uma lista de artistas de MPB consagrados como Gilberto Gil, Doces Bárbaros, João Bosco (Sítio do Pica Pau Amarelo, 1977); Maria Bethânia e Fafá de Belém (Plumct Plact Zum, 1983); Chico Buarque, Elis Regina, Milton Nascimento, Ney Matogrosso, entre outros (Arca de Noé 1 e 2; 1979 e 1980). Esta estratégia da indústria fonográfica permitiu a estes artistas serem apresentados para um novo público, infantil, de forma diferenciada. É importante notar que todos estes discos ainda encontram-se em catálogo hoje.

\section{As novas mídias e os relançamentos}

Finalmente, é necessário dizer também que a indústria fonográfica contribuiu para a longevidade da MPB e de seus artistas. Toda a obra destes artistas ganhou um sopro de ar, por exemplo, quando foram relançadas em cd entre o final dos anos 80 e início dos anos 90. Muitas discografias que estavam fora de catálogo em vinil foram apresentadas para um novo público no formato de cd. Além disso, no caso de Caetano Veloso, por exemplo, sua obra é constantemente reeditada e já foi embalado em várias caixas de cds comemorativas, o que permite dizer que sua obra está sempre acessível para novos consumidores. O mesmo aconteceu com Chico Buarque e Gilberto Gil. Gravações de Bethânia e Gal da obra de Chico e Caetano viraram songbooks específicos nas mãos da gravadora Universal: Bethânia canta Caetano, Bethânia canta Chico Buarque e Gal canta Caetano (também existe um Gal canta Caetano lançado pela Sony-BMG). Além disso, vários artistas gravaram discos específicos com composições de Chico e Caetano. Vânia Bastos gravou um disco só com composições de Caetano, por exemplo, enquanto Cida Moreira e Ney Matogrosso preferiram o cancioneiro de Chico. Recentemente, em 2009, a Som Livre lançou um cd duplo com cantores e cantoras interpretando a obra de Chico. Eu mesmo produzi um Cd para a antiga Sony-BMG (atual Sony) reunindo faixas raras de intérpretes femininas cantando canções de Gilberto Gil, chamado Gil na Delas.

\section{E no Final, os Frutos...}

Acredito que todos os fatores apontados contribuíram de alguma forma para que estes artistas em particular continuassem em evidência, com maior ou menor intensidade de acordo com suas características particulares. Porém, entendo também que estes fatores em conjunto propiciaram a estes artistas uma exposição midiática que poucos artistas obteriam hoje. É normal que qualquer evento ou disco ou livro ou show destes artistas ganhe a primeira página dos cadernos de cultura dos principais jornais do país além de espaços disputadíssimos na TV, independente do conteúdo destes trabalhos: o show de Bethânia é notícia mesmo antes de se saber como ele será, assim como o processo de criação de um novo disco de Caetano ou de um livro de Chico Buarque. De certa forma, todos eles colhem os frutos de uma carreira que, como previu Midani, foi feita aos poucos, mas de forma consistente e duradoura. 
Tabela 1. MPB: Participação na lista dos 50 mais vendidos do Nopem (1965/1999)

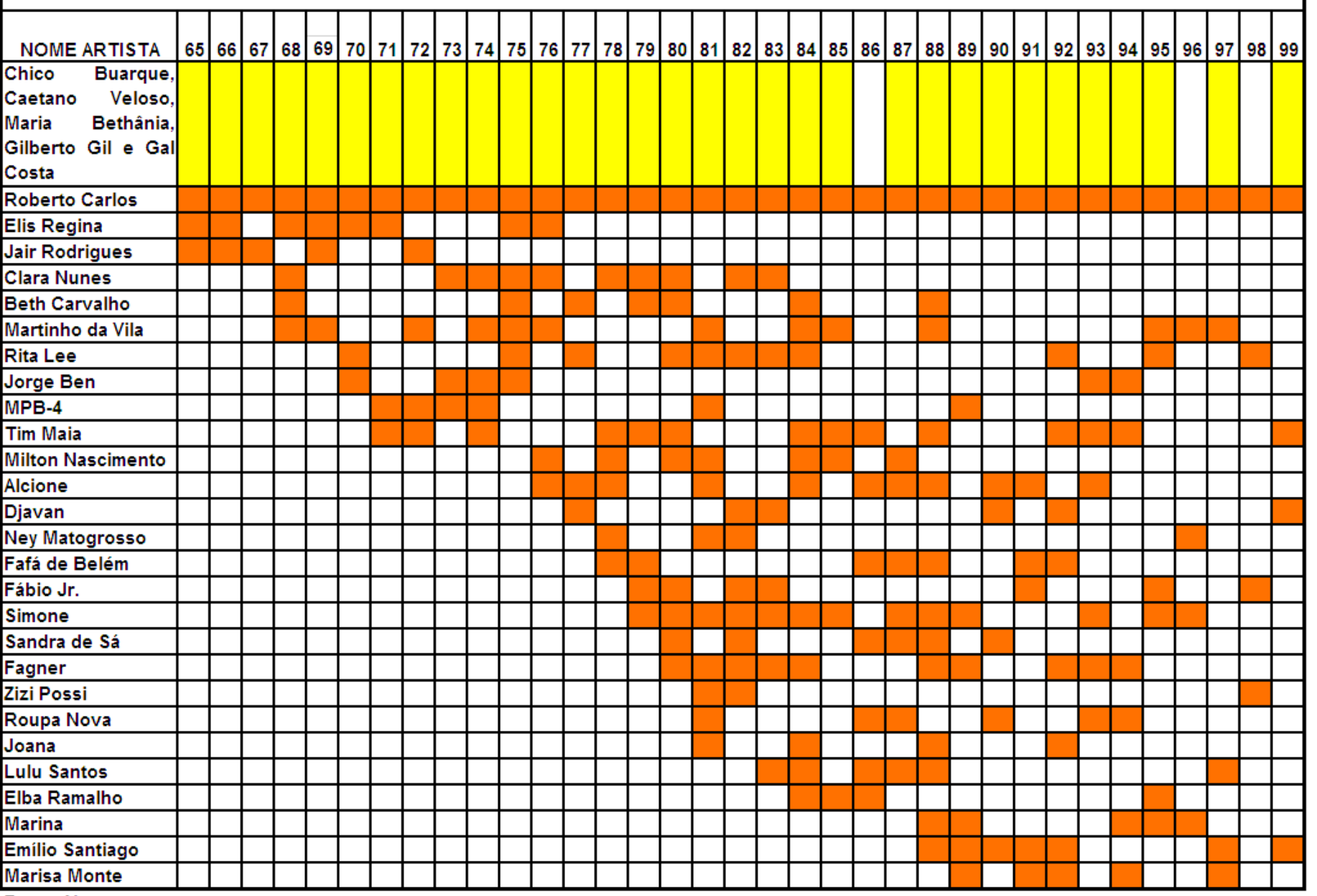

Fonte: Nopem

Tabela 2. MPB: Participação na lista dos 50 mais vendidos do Nopem (1965/1999)

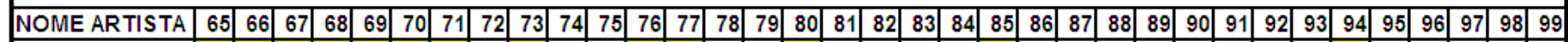
Chico Buarque

Caetano Veloso

Maria Bethânia

Gilberto Gil

Gal Costa

Fonte: Nopem

\section{Referência Bibliográfica}

BOURDIEU, Pierre. As Regras da Arte. São Paulo: Cia das Letras, 1996.

FAVARETTO, Celso F. Tropicália: Alegoria, Alegria. 4. ed. São Paulo: Ateliê Editorial, 2007.

KALILI, Narciso. “A nova escola do samba” In: Realidade 8, 1966: 116-125.

MIDANI, André. Música, Ídolos e Poder. Do vinil ao download. São Paulo: Editora Nova Fronteira, 2008.

NAPOLITANO, Marcos. Seguindo a canção. São Paulo: edição digital, 2010.

VASCONCELLOS, GIlberto. Música Popular: de olho na fresta. Rio de Janeiro: Graad, 1977. 
VELOSO, Caetano e FERRAZ, Eucanaã (org). Letra Só/Sobre as Letras. São Paulo: Cia das Letras, 2003.

VICENTE, Eduardo. Música e Disco no Brasil. Tese de doutorado não publicada, São Paulo: ECA/USP, 2002.

VICENTE, Eduardo. "Música e Disco no Brasil: a trajetória de André Midani". In: Significação: Revista de Cultura Audiovisual, v. 29, p. 115-142. Annablume, São Paulo: 2009.

WISNIK, Guilherme. Caetano Veloso. São Paulo: Publifolha, 2005. 